Instructions for authors, subscriptions and further details:

http://brac.hipatiapress.com

\title{
Resistencia y Dolor. Tracey Emin: \\ La Belleza de lo Pecaminoso y la Fragilidad de lo Vulnerable
}

Fernando Sáez Pradas ${ }^{1}$

1) Departamento de Dibujo, Universidad de Sevilla. España

Date of publication: February $3^{\text {rd }}, 2015$

Edition period: February 2015 - June 2015

To cite this article: Sáez Pradas, F. (2014). Resistencia y Dolor. Tracey Emin: La Belleza de lo Pecaminoso y la Fragilidad de lo Vulnerable. Barcelona, Research, Art, Creation, 3(1), 13-32. doi: 10.4471/brac.2015.02

To link this article: http://dx.doi.org/10.4471/brac.2015.02

\section{PLEASE SCROLL DOWN FOR ARTICLE}

The terms and conditions of use, except where otherwise noted, are related to the Open Journal System and to Creative Commons Attribution License (CCBY). The indication must be expressly stated when necessary. 


\section{Struggle and Pain. Tracey Emin: The Beauty of Sin and the Fragility of the Vulnerable}

Fernando Sáez Pradas

University of Sevilla

(Received: 16 July 2014; Accepted: 30 November 2014; Published: 3 February 2015)

\section{Abstract}

This article, written in light of the latest news on Tracey Emin, the British artist who faced a barrage of criticism of every kind when her work was shortlisted for the Turner Prize, focuses on the artist's most significant creations, considering their meaning then and now. At present, Emin and her work My Bed (1998) once again find themselves in the cultural media spotlight after the piece reached $£ 2.2$ million at Christie's Auction House following the sale by the Saatchi Gallery. The revelation has reopened the debate which started when the work was unveiled and presents the opportunity to examine how the wound inflicted on traditional British decency has healed. Sufficient time has passed to make a reliable assessment of the reach and impact of the work and consider what has become of the controversy it originally sparked. Alongside a critique of $\mathrm{My} \mathrm{Bed}$, the article will look at the factors which have proved most decisive in shaping the artist's work including influential works of art and aspects of Emin's life.

Keywords: Privacy, transgression, taboo, sex, drawing 


\section{ResistenciayDolor.TraceyEmin: La Belleza de lo Pecaminoso y la Fragilidad de lo Vulnerable}

Fernando Sáez Pradas

Universidad de Sevilla

(Recibido: 16 Julio 2014; Aceptado: 30 Noviembre 2014; Publicado: 3 Febrero 2015)

\section{Resumen}

Tras las últimas noticias acaecidas sobre Tracey Emin, la artista británica que desató una nube de críticas de todo tipo sobre su trabajo cuando fue nominada al premio Turner, desarrollamos en este artículo un análisis focalizado en sus obras más significativas, centrándonos en lo que significaron y lo que suponen hoy en día. Actualmente la artista y su obra My bed (Mi cama) (1998) vuelven a ocupar todas las portadas de la prensa especializada dada la cifra de 3,2 millones de euros alcanzada en subasta en la casa Christie's a través de la galería Saatchi. Con esto se abre de nuevo el debate que la pieza originó en su momento y veremos cómo ha cicatrizado la herida que supuso al decoro británico. Ya hay cierta perspectiva histórica para analizar de manera fiable cual ha sido el alcance y la trascendencia de la obra y en qué se ha traducido tanta polémica. En paralelo a la obra $M y$ bed, profundizamos en aspectos que han resultado ser decisivos para la conjunción de todos los elementos que han dado forma a su trabajo: obras significativas y aspectos de su vida convertidos en producto artístico.

Palabras clave: Privacidad, transgresión, tabú, sexo, dibujo 


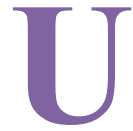

no de los grandes fenómenos de la década de los 90 en la escena internacional ha sido el conocido bajo las siglas YBA's, Young British Artist, o su traducción al español "Jóvenes Artistas Británicos". Una amalgama de adolescentes heterodoxos que se proyectaban al mundo utilizando métodos poco convencionales hasta entonces, aprovechándose de mecanismos más propios del marketing que de los cauces artísticos tradicionales. Damien Hirst, Sarah Lucas, Rachel Whiteread y Chris Offili fueron algunos de ellos, pero en esta investigación nos centraremos en la artista que posiblemente generara más confusión, discusión y controversias. Nos referimos a la británica Tracey Emin, con cuyo trabajo revolucionó el panorama internacional convirtiendo a Londres en el principal escaparate del arte contemporáneo. Fueron dos las obras de la artista que ocuparon la mayor atención mediática, la primera Everyone I have ever slept with 1963-1995 (Todas las personas con las que he dormido), una tienda de campaña con nombres bordados en su interior, y la segunda, My bed, una cama de matrimonio deshecha con objetos de diversa índole a su alrededor. Transgresores aires de cambio que respondían a nuevos contextos sociopolíticos de la era post Thatcher.

En Inglaterra se produjeron transformaciones importantes en los mecanismos para promocionar el arte que marcarían el futuro inmediato del joven arte británico. Fueron tres los ejes principales que promovieron dicho cambio: por un lado los Degree Shows, unas exposiciones frescas realizadas por jóvenes recién graduados que llamaron la atención de los medios de comunicación especializados y galerías; las inversiones realizadas por Charles Saatchi, magnate iraquí afincado en Londres, y la publicidad feroz que hacía de sus adquisiciones; y por último y muy trascendente, la relevancia que adquiere el Turner Prize, un premio dirigido a artistas británicos menores de cincuenta años (Gili, 2001).

Una nueva generación de artistas surgía así tras la era Thatcher y el 20 de octubre de 1999 la candidatura de Tracey Emin (Margate, 1963) al premio Turner se hacía mundialmente conocida. Toda clase de medios de comunicación británicos e internacionales se hacían eco de la noticia. La obra se titulaba My bed y, aparentemente, consistía en una cama de matrimonio, deshecha, sucia y con una variedad de objetos esparcidos por el suelo que nos indicaban los momentos de excesos que había vivido la artista en el lugar. 
Podíamos ver botellas vacías, pañuelos usados, periódicos, unas zapatillas de casa, etc. Un sinfín de suciedad y desorden que se convertía en candidato a ganar el premio de mayor dotación económica a las artes que se concede en Reino Unido. ¿Podría responder tanto desencanto, desarraigo e incluso falta de respeto a la institución y la maquinaria artística, a la profunda crisis económica y social de las políticas conservadoras de Margaret Thatcher?

Resulta significativa la importancia y el debate que ha suscitado su trabajo desde hace años, hoy en boga dada las elevadas cifras económicas que ha alcanzado la pieza My bed en subasta a través de la galería Saatchi. El galerista pretende así recaudar fondos que le permitan continuar con la política de acceso gratuito a sus instalaciones. A pesar de las controversias que genera la artista británica cada vez que aparece en los medios de comunicación, la herida que Tracey Emin le produjo al arte británico en la década de los 90, ha cicatrizado de tal modo, que lo que en su momento fue un revulsivo considerado vulgar, hoy forma parte de la estructura clásica británica; y actualmente ya es académica en la Real Academia de las Artes (Royal Academy of Arts).

\section{Biopic (Biografía Novelada)}

Estudió arte en el Royal College of Art de Londres y posteriormente filosofía. Durante estos primeros años, junto con su compañera Sarah Lucas, abrió una especie de galería-tienda llamada The shop, donde vendían dibujos, camisetas y objetos personales entre otras cosas. Poco después, en 1994, la galería White Cube, una de las más importantes del país, realizó una exposición para Tracey Emin, llamada My Major Retrospective, una especie de efeméride de su propia existencia en la que exponía toda clase de obras, incluyendo juguetes, diarios, dibujos, fotografías... todo relacionado con aspectos muy privados de su vida. Comenzábamos, así, a darnos cuenta de los episodios más oscuros que había atravesado la artista, una truculenta vida privada que iba haciéndose, poco a poco, cada vez más conocida: marginación en la escuela; violada a los trece años; padre y madre prácticamente ausentes en su educación; sufrió de alcoholismo; tuvo problemas de alimentación; perdió dos embarazos, etc. (Elliott \& Schnabel, 2008).

Estos aspectos biográficos serán el fundamento y la base de todo su trabajo. Situar al espectador continuamente en lugares límite de la razón, la moral, la ética y lo legal y transgredir las líneas que marcan lo decoroso serán los ejes 
que articulen la relación de la obra de Emin con el espectador. Su valentía radica en enfrentarse frontalmente con el dolor, al que utiliza como elemento catártico para trascender a través de su obra. Una realidad tan cruda como delicada introduce al que la ve, en un bucle de contradicciones acabando por no saber cuál de las dos descripciones pesa más. Aunque "la imaginación de lo ilícito tiene un alcance limitado" (Nabokov, 2010, pág. 31), veremos cómo Emin es capaz de atravesar fronteras que creíamos infranqueables.

Estamos ante una obra dura, árida, frágil. Una amalgama donde vida y obra se entremezclan convirtiéndose en una misma cosa, y en la que se nos hace difícil encontrar las líneas que las separan, como se nos hacía difícil encontrarlas en Dalí y Warhol, pioneros en estas cuestiones. Manifestaciones multidisciplinares serán las que den forma al cuerpo discursivo: instalación, pintura, vídeo, escultura, fotografía, etc. Aunque, si hay algo que sea una marca identitaria de su trabajo, ésto será el dibujo. Una disciplina que predominará y será una constante desde sus inicios, hasta la actualidad.

\section{La Primera Gran Sorpresa: \\ “Everyone I have ever slept with 1963-1995”, una Tienda de Campaña}

“¿Qué sucede cuando una cosa ya no cumple su función? ¿Sigue siendo la misma cosa o se ha convertido en otra? Cuando arrancas la tela del paraguas, ¿el paraguas sigue siendo un paraguas? Abres los radios, te los pones sobre la cabeza, caminas bajo la lluvia, y te empapas. ¿Es posible continuar llamando a ese objeto un paraguas? En general, la gente lo hace. Como máximo, dirán que el paraguas está roto. Para mí eso es un serio error, la fuente de todos nuestros problemas. Puesto que ya no cumple su función, el paraguas ha dejado de ser un paraguas. Puede que se parezca a un paraguas, puede que haya sido un paraguas, pero ahora se ha convertido en otra cosa. La palabra, sin embargo sigue siendo la misma" (Auster, 2009, pág. 88). 


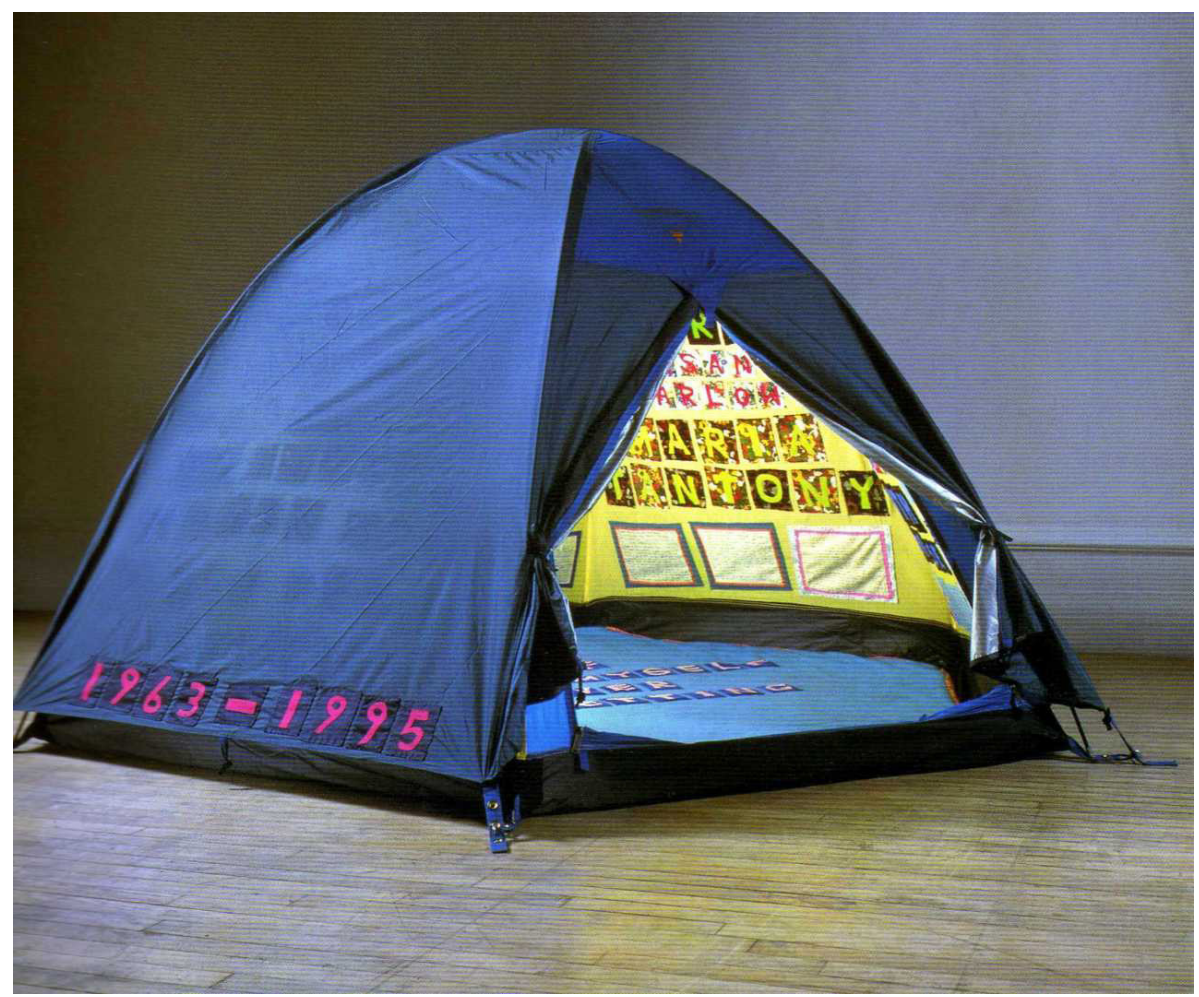

Figura 1. Tracey Emin, "Everyone I have ever slept with 1963-1995” (“Todas las personas con las que he dormido"), 1995. (C) White Cube, Gallery.

Dos cosas importantes: el objeto y la palabra. Ahora bien, ¿podremos seguir llamando a la tienda de campaña, tienda, o a la cama, cama? ¿Se han convertido en otra cosa? Estamos ante una reconstrucción duchampiana, una descontextualización tan brusca como la que hiciera el artista francés, en 1917, con su obra Fontaine (La fuente), estableciendo ahora para la tienda un nuevo código, un valor diferente.

Atendiendo, en primer lugar, a la tienda de campaña (Fig.1.) y observando su título, cotejamos que una traducción literal de éste sería Todas las personas con las que he dormido entre 1963-1995. A simple vista vemos una tienda, de las llamadas tipo iglú, azul en su exterior donde casi a ras de suelo vemos dos cifras numéricas 1963-1995, en su interior aparecen cosidos los nombres de 
todas las personas que han compartido cama con la artista. Una horquilla que abarca desde sus amantes hasta a su propio hermano Paul. Un objeto industrial, una tienda de campaña que podríamos adquirir en cualquier establecimiento especializado o en unos grandes almacenes. Nada la hace especial. Entonces, ¿sigue siendo este objeto una tienda? Si no es así, ¿qué es ahora y por qué?

Rápidamente comenzamos a percibir parte de las intenciones que tiene la artista, y empezamos a elucubrar qué habrá en su interior, qué hace que esta tienda sea diferente a las demás y qué la convierte en una pieza de museo. Aunque esta última cuestión ya no es posible, dado que la pieza se perdió en el incendio del almacén en el que se encontraba, generando con ello gran estupor por la pérdida de numerosas obras (los hermanos Chapman y Damien Hirst también fueron perjudicados), pero aumentando la popularidad de la artista (Fig. 2.).

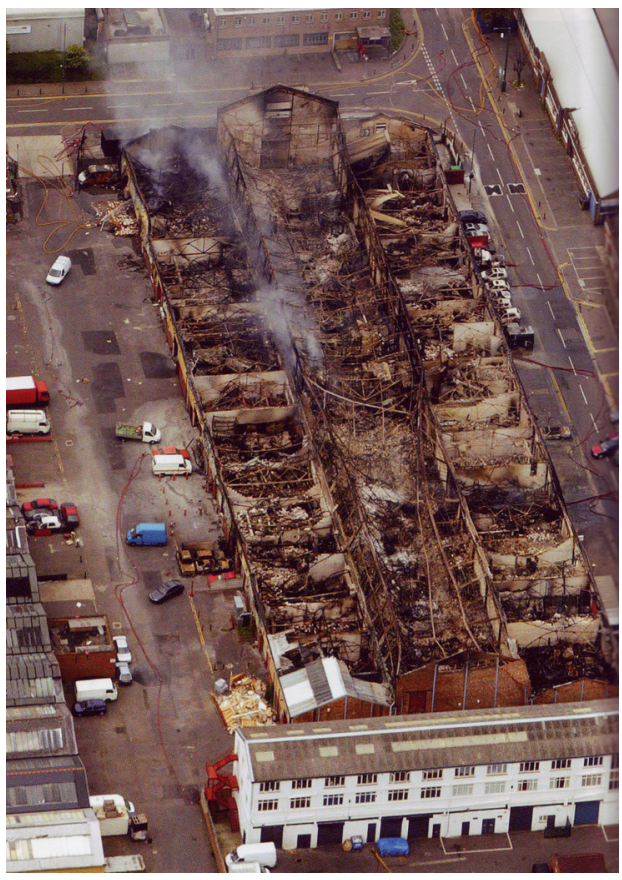

Figura 2. Incendio en los almacenes de Momart, en Leyton, 2000. (C) Rex Features. 
Una primera aproximación a la pieza nos inicia en generarnos la visión que Tracey Emin tiene con respecto al hombre y el sexo, a veces para ella, una misma cosa, dos elementos fusionados en una misma idea. La artista británica ha otorgado a la tienda un nuevo valor, que la convierte en una especie de "harén invertido" (Martín, 2008), invirtiendo el papel histórico en la relación hombre-mujer y su rol activo-pasiva, dominador-dominada. Ella es la dueña del espacio. Antropológicamente tenemos incorporadas las funciones que históricamente se le han atribuido al sexo masculino y al sexo femenino, mientras que la mujer se quedaba en la cueva, el hombre era el que cazaba, el recolector. Actitudes activo-pasivas en las que la mujer cuidaba y criaba y el hombre protegía y alimentaba con sus conquistas animales.

En El baño Turco de 1862, a través de la visión masculina, Ingres hace una referencia literal al concepto de harén clásico. También Picasso lo hizo en obras como El harén, y planteó sus modos de entender el sexo en Las señoritas de Aviñon o en grabados de la Suite Vollard. La historia ha hecho que estemos más familiarizados con la visión masculina, circunscrita a unas prácticas y unos roles sexuales incuestionables, en detrimento de la mirada femenina. Aún más conflictiva se presenta la cuestión, cuando a la visión femenina se le suman los roles que tradicionalmente se han entendido como masculinos, produciéndose así una colisión emocional que nos llena de dudas sin que podamos dar una solución, al menos de manera automática, ya que ninguno de los resortes que tenemos para defendernos de estos ataques funcionan aquí, pues ni el material, ni el procedimiento, y ni siquiera su concepto pueden salvar, en un primer estadio, a esta obra de la quimera académica.

La tienda de Emin es manifiestamente conceptual. Está rescatando con esta obra los ready-made de Marcel Duchamp. Obras como El Gran Vidrio, o La fuente guardan lecturas relacionadas con el sexo, con las bajas pasiones; pero, será en Etant Donnés: $1^{\circ}$ La chûte d'Eau; $2^{\circ}$ Le gaz d'Éclairage (Dados: $1^{\circ} \mathrm{La}$ Cascada, $2^{\circ} \mathrm{El}$ Gas de alumbrado) de 1946-1966, donde encontramos una relación directa con la obra de Tracey Emin. El deseo de observar lo que ocurre dentro, la curiosidad y el morbo irrefrenable acaba convirtiendo al espectador en un voyeur, obligándolo sin que pueda negarse a violar una intimidad incómoda.

Una vez dentro, vemos como con delicadeza y orden, Tracey Emin ha bordado sobre trozos de tela que luego ha cosido a la tienda, los nombres de las personas con las que ha compartido cama. Recupera así una de las actividades entendidas como históricamente femenina: la costura; sólo habría que recordar el mito de Aracne o Penélope. La tienda se convierte en refugio 
como la caverna para el mono de Kubrick, un hogar, una cueva, un vientre, un útero. Para adentrarse, el espectador ha tenido que cruzar la abertura vertical de la entrada, acabando de este modo por convertirse en un falo, en un acto de contraposición de elementos sexuales. La obra de Tracey Emin ha adquirido todas las connotaciones que tuvo el monolito - continuando con Kubrick- y el espectador se ha transmutado en mono y siente y ordena en su interior el desafío, el miedo y la curiosidad, desarrollando por último la valentía en el mejor de los casos, si acaba por penetrar en la intimidad de la artista. Ya hemos visto esta acción en otros artistas, Pedro Almodóvar incluye en su película Hable con ella, 2002, un cortometraje mudo llamado El amante menguante, donde un diminuto hombre camina sobre una mujer como si se tratara de un escenario natural -un campo, o un parque- hasta que encuentra su sexo y entra en el cuerpo de la mujer a través de él, también Niki de Saint Phalle cuando, en 1966, presenta su obra She a cathedral donde hacía que el público recorriera el interior de una gigantesca escultura femenina entrando a través de su órgano sexual. Una especie de parto al revés, una vuelta al hogar.

Si las puertas de la percepción se depurasen / todo aparecería a los hombre como realmente es: infinito. / Pues el hombre se ha encerrado en sí mismo hasta ver / todas las cosas a través de las estrechas rendijas de su caverna. (Blake, 1793).

Una vez atravesada la puerta, estamos en otra esfera, un lugar sagrado, un santuario y aquí sin duda la palabra es importante, con ella Tracey Emin no insinúa sino que señala directamente. (Fig. 3.) Nada de mensajes subliminales. Aquí nos muestra el nombre, dejando a voluntad del espectador, decidir cuáles habrán sido los porqués. ¿Qué valor tiene la escritura?, ella lo dejó claro, "realmente lo mío es la escritura (...) son mis palabras lo que hacen de mi arte algo único" (Martín, 2008, pág. 28). Porque ¿qué es el ser humano sino fundamentalmente lenguaje?, ya decía Heidegger: "El lenguaje es la casa del ser y la morada de la esencia del hombre", el lenguaje cosifica, nomina, es la creación por excelencia en la que se vierte el carácter simbólico del ser humano. Con estos retablos de nombres se inicia el misterio y la elucubración. Todas las dudas nos asaltan y comienzan los juicios inquisitorios, en el peor de los casos, sobre el bien y el mal, lo bueno y lo malo, apelando a una moralidad ancestral donde no se perdona el incesto (Bataille G., 2007, págs. 204-226). 


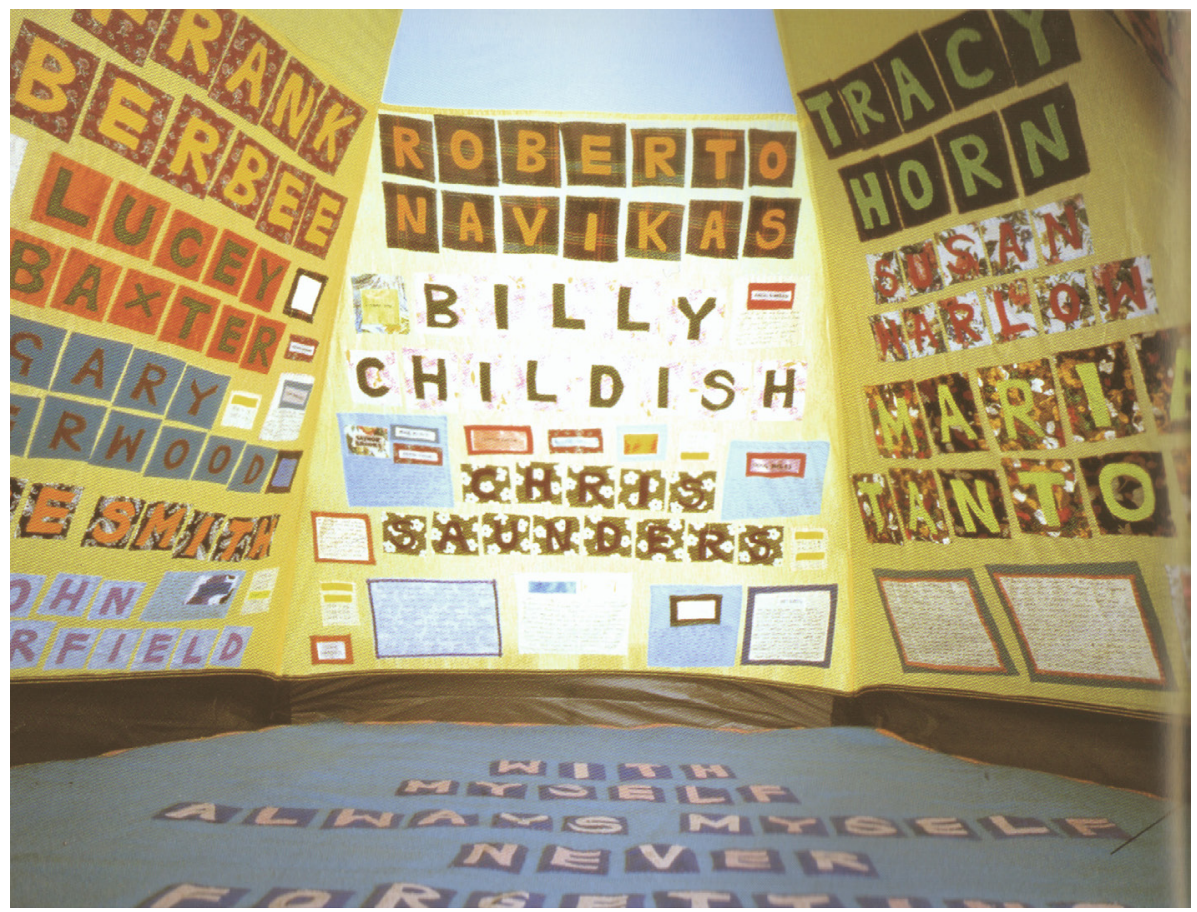

Figura 3. "Tracey Emin, Everyone I have ever slept with 1963-1995” ("Todas las personas con las que he dormido"), 1995. (C) White Cube, Gallery.

En estados emocionales intensos, algunos individuos sienten la necesidad de la exteriorización, refiriéndonos a la escritura en este caso, una actividad que media entre el ser y la cultura y que supone una eternidad en la expresión, pues en su función va intrínseca la permanencia (Choza, 2013). Esto supone un reconocimiento a algo, del mismo modo que lo hacían los menhires o los obeliscos, o en los monumentos donde se conmemora a algún héroe, lleno de símbolos y textos. La tienda de Emin sería otro objeto conmemorativo, una especie de monumento para pobres, relativo a un mundo lumpen, donde se reconocen nombres de héroes - $\mathrm{O}$ villanos- que pertenecen a su submundo. Trofeos y conquistas que quedan anotados a través de lo escrito como si de un libro de firmas se tratase. Ya en el Imperio Romano la escritura espontánea sobre paredes era una cuestión extendida y así han llegado hasta nuestros días, recogidas en las catacumbas romanas o en las ruinas de Pompeya, entre otros lugares. 


\section{BRAC - Barcelona Research Art Creation, 3(1)}

\section{Exposición Pública de un Encierro Voluntario}

La diversificación y especialización de ritos y costumbres de la vida social, y el aumento de su número, pudo dar lugar a una diferenciación incipiente de los ámbitos de lo público, lo privado y lo íntimo, al aumento del contenido de los tres ámbitos y al juego de trasvase de contenidos entre ellos. (Choza, 2013, pág. 147).

En un primer instante Tracey Emin intenta disimular esa ansia de exposición pública refugiando sus pensamientos y experiencias vitales en un lugar cerrado pero, ¿qué ocurre después de la tienda de campaña? Será en Exorcism of the Last Painting I Ever Made (Exorcismo de la última pintura que hice), acción realizada en febrero de 1996, donde la idea de sobreexposición aparece de un modo más destacado.

En esta obra, la artista se encerró durante tres semanas en el interior de la galería Andreas Brändström de Estocolmo. Construyó su estudio en el interior de la galería, trabajando allí en una especie de encierro voluntario durante el tiempo que duró la exposición. Hay que destacar el sistema que se empleó para que los visitantes interactuaran con la artista: unas mirillas. A través de ellas, se podía observar toda la actividad que Tracey Emin desarrollaba en su interior. Una mezcla entre el fenómeno Big Brother surgido a finales de los 90 y el Etand Donnés. La diferencia entre la obra de Duchamp y la de Emin, está centrada en que lo que veíamos en la de ésta, no era un cuerpo inerte y pasivo, sino todo lo contrario. Una mujer en plena actividad y reconciliándose con su trabajo pictórico, pues unos años atrás había quemado toda su producción pictórica, como lo hicieron otros antes -Francis Bacon, por ejemplo-, tras caer en una profunda depresión.

Son muchas las obras y los artistas en los que podemos encontrar el concepto de voyeur al que hacemos referencia. Degás y Picasso son dos ejemplos destacables y de los tradicionalmente más conocidos, aunque son muchos más. Sexo y voyerismo se entremezclan hasta el extremo en la obra Seedbed (Semillero), una performance que Vito Acconci llevó a cabo en la Sonnabend Gallery de Nueva York, en el año 1972. Allí se escondió bajo una rampa durante tres semanas, para masturbarse durante ocho horas al día mientras murmullaba frases como "You're pushing your cunt down on my mouth" o "You're ramming your cock down into my ass" (Saltz, 1972), expresiones soeces con una intención clara de incomodar. La relación que 
Aconcci establece con el espectador es diferente a la que determina Tracey Emin en su acción, mientras el artista estadounidense se esconde para importunar al público, Emin se refugia y no le importa que la observen en su encierro. Aquí la tienda de campaña se ha convertido en un lugar mayor, en cuyo interior podemos encontrar físicamente a la artista, aunque ambos, tanto Acconci como Emin, desarrollan desde su cobijo, su trabajo, interactuando de un modo directo con el espectador.

Allí se dedicó a pintar, utilizando este encierro como un acto de liberación -valga la paradoja-, procedimiento, el de la pintura, que no usaba desde que abortó por segunda vez. No son extraños estos encierros en el contexto del arte contemporáneo, ya Beuys lo hizo en la galería Block de Nueva York, durante tres días y, camuflado entre sábanas y fieltro, con un coyote. Utilizando al "animal sagrado, dios de los indios, elegido como símbolo de américa" (Bernárdez, 2003, pág. 58), para reflexionar sobre la relación entre el arte europeo y el americano.

\section{De cómo una Cama Puede Convertirse en Arte: My Bed}

Utilizando esta performance como puente entre un lugar y otro, la siguiente obra a la que haremos referencia será My bed (Mi cama), de 1998, una obra muy mediática, finalista del Tuner Prize, que supuso un punto de inflexión significativo en la trayectoria de Tracey Emin, aunque por su repercusión y contenido haremos extensible esta importancia a todo el arte británico de los 90, al que situó en un lugar sin retorno. Una pieza que tiene una conexión importante con las dos obras anteriores, una evolución de la tienda de campaña y la performance.

Desde el punto de vista formal, Tracey Emin nos presenta una cama de matrimonio deshecha, con sábanas blancas, sucia, a sus pies una alfombra azul sobre la que quedan esparcidos todo tipo de objetos: pañuelos usados, cigarrillos, condones, un tubo de vaselina, botellas vacías..., entre otras cosas. "A primera vista, los objetos sexuales son ocasión para una continua alternancia entre repulsión y atracción” (Bataille G., 2007, pág. 75). Un justo testigo de la noche al filo del abismo de la que acaba de sobreponerse (Fig. 4.).

Cuando me desperté estaba tan deshidratada que pensé que si no bebía agua me moriría. De alguna manera, no sé cómo, me caí y me arrastré 
a cuatro patas hasta la cocina, cogí una bebida, lentamente di unos pocos sorbos, y volví a la habitación, y allí estaba yo, y todo era agg..., era asqueroso. Y miré hacia la cama y pensé: "Oh, Dios mío, podía haber muerto aquí", y así era como me habrían encontrado. Y entonces, pasé repentinamente de estar horrorizada ante lo que tenía delante, a sentirme distanciada de todo aquello que de repente percibí como algo bello. Me imaginé la escena fuera de aquel contexto, congelada, fuera de mi cabeza en otro lugar (Freeman, 2006, págs. 251-252).

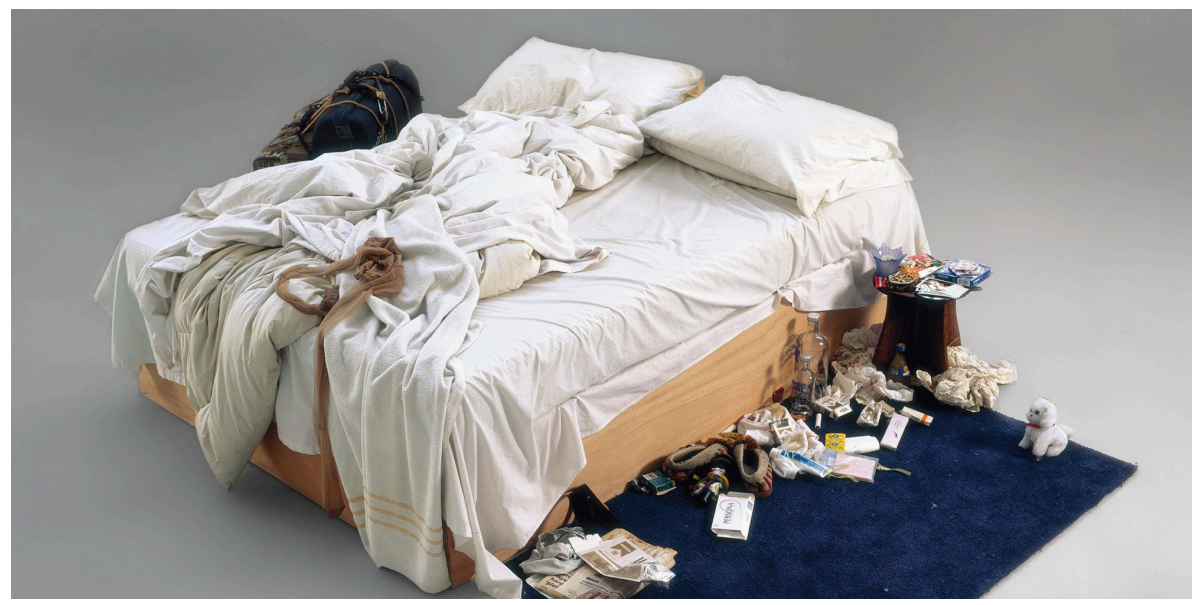

Figura 4. Tracey Emin, "My bed” (“Mi cama”), 1998. (C) Saatchi Gallery.

La separación mental entre la obra y la artista hizo que se marcaran nuevas líneas conceptuales y que nos vengan a la memoria los banquetes que el nuevo realista Spoerri hacía en la Galería J de París, a la que convirtió en un restaurante donde quedaba para cenar con sus amigos. Una vez finalizada la comida, pegaban todo lo que habían usado sobre la mesa, en las que podíamos ver platos, vasos, cubiertos... y la colocaban en posición vertical como si de un cuadro tradicional se tratara. Con ello tornó en arte, a un conjunto de objetos que habían sido testigos de la ceremonia de la comida; objetos de un rito transmutados en arte. De este modo, se transforma en creación, no una actividad, sino su final, con la diferencia de que, en este caso, Daniel Spoerri si tenía una conciencia y unos objetivos generales marcados acerca de cómo 
acabaría su acción; pero, que en Emin no fue así. Mientras Spoerri hizo un teatrillo como excusa para concluir una pieza artística, Tracey Emin no tenía un guion, y hasta que no se distanció de un modo consciente, no fue capaz de ver la dureza de la realidad a la que se había sobrepuesto. Un impacto emocional tan grande como subversivo, en el que acabó por encontrar la belleza de lo pecaminoso en un lugar inhóspito, tan hosco y duro como el espacio que encontramos, 200 años antes, en Saturno devorando a un hijo, o en La balsa de la Medusa, en cuya atmósfera sobrevuelan las debilidades y miserias del ser humano (Bataille G., 2007, págs. 146-152).

Eliminando la ironía y el humor de Piero Manzonni cuando realizó su Mierda de artista, en 1960, Tracey Emin transmuta este detritus igual que el artista italiano. Ha modificado el concepto del contenido, y ha logrado convertir en pieza de museo, en obra artística, un escenario lleno de basura. Un pequeño estercolero que hace al hombre enfrentarse a su lado más lumpen, sórdido y desolador. A una parte oscura del subconsciente que, en el mejor de los casos, podemos tener medianamente adormecida. No representa, presenta. Y este gesto, en el que hay cierta violencia contenida, hace de esta pieza un lugar importante para detenerse o huir. “¡Ah, dijo el pájaro. El género humano no puede soportar demasiada realidad” (Eliot, 2012, pág. 85).

La obra fue expuesta entre los meses de octubre de 1999 y enero del 2000 en la Tate Britain -que no en la Tate Modern-y las dos primevas veces que se exhibió, la pieza llevaba una soga colgando sobre la cama, aunque más tarde, eliminó esta idea.

Existe una brutalidad en la cama de Tracey Emin, extensible a la gran mayoría de sus trabajos, que desborda a quien la ve, "su fuerza está en ser capaz de decir lo que no puede decirse y mantenerse viva después" (Martín, 2008), con una verdad que se clava como concertina. No hay eufemismos, no hay metáforas, no hay ocultación. Se cumplen en su trabajo, de este modo, dos particularidades notables: pasa de lo privado a lo público y eleva el prejuicio a juicio.

Este derramamiento de todo lo que pertenece a la esfera privada y que ella acaba por convertirlo en público, ha hecho de su obra un lugar insoportable debido al exceso en la dosis de realidad. Encontrarse a sí mismo como tarea significa situarse al borde del abismo, (Kierkegaard, 2007), y esto da miedo, genera un sentimiento de estrechamiento, de angostamiento, de ansiedad... Una angustia de la que ha conseguido desprenderse verbalizándola, compartiéndola sin pudor, como si de un acto psicoanalítico se tratara, ha pasado de lo inconsciente a lo consciente. 
La preocupación por los ciclos biológicos fundamentales del ser humano-ya sean biográficos o no- y de los que destacaremos la muerte y la reproducción, preocuparon también a otro compañero de su generación: Damien Hirst. Tomaremos como ejemplo de ello la obra A Thousand Years, de 1990, una estructura rectangular de $213 \times 427 \times 213 \mathrm{~cm}$. en cuyo interior hay una cabeza de vaca pudriéndose, donde nacen larvas que se transforman en moscas, y que posteriormente completan su ciclo vital falleciendo cuando impactan con un circuito eléctrico situado dentro. Nacer, crecer, reproducirse y morir, un esquema conceptual de las preocupaciones de Hirst que tuvieron su eco en el trabajo de Tracey Emin. Ambos fueron los artistas de esta generación que más proyección internacional han tenido, y Hirst ha encabezado durante muchos años la lista de los artistas más importantes del mundo.

En My bed, cierto componente religioso sobrevuela; la idea de tocar fondo; el morir conceptualmente para renacer trayendo consigo la verdad revelada por el subconsciente; la percepción del escenario que tiene Tracey Emin como si fuera un sujeto externo, ya trascendido; la idea de culpa; la moralidad, el bien y el mal; la transmutación de la materia como si de una transustanciación se tratase... "En la historia del erotismo, la religión cristiana desempeñó una función clara: su condena" (Bataille G., 1997, pág. 97).

\section{El Dibujo y su Componente Narrativo}

En paralelo a las obras a las que hemos hecho referencia, Tracey Emin ha desarrollado a lo largo de su carrera una complejísima y numerosa serie de dibujos, una colección gráfica imprescindible para cualquier estudioso de su trabajo. Gran parte de ellos quedan recogidas en la publicación One Thousand Drawings (Mil dibujos), un compendio de mil dibujos realizados sobre papel con diferentes técnicas, desde 1988 hasta 2007.

Estos dibujos han resultado ser una obra muy significativa y completa que explican perfectamente todas las inquietudes que ha desarrollado la artista a lo largo de su vida. En ellos vemos una amplia iconografía relacionada con su entorno y su vida cotidiana: la familia, animales, paisajes..., un gran número de preocupaciones aparecen en este legado gráfico, entre las que destacaremos la que será una constante: el sexo.

Antropológicamente, desde que el ser humano ha tenido relaciones sexuales, éstas han sufrido un gran cambio conceptual, las acciones han pasado de lo animal a lo humano provocado por una transformación intelectual 
en el proceso: "La sexualidad en el hombre evolucionó desde una práctica sin vergüenza hasta una experiencia pudorosa, que acabó derivando en lo que conocemos como erotismo. Una transformación de animal a humano" (Bataille G., 2007, pág. 35) ¿Puede trascender la artista a través del sexo y en partes iguales su lado animal y el más intelectual? cuando el sentido común y la razón desparecen, estamos abocados a adentrarnos en un mundo terrible, "el sueño de la razón produce monstruos" decía Goya. No sabemos con certeza si lo que duerme en Emin es la razón o el corazón, en cualquier caso, vemos en sus dibujos un mundo terrible. Son trabajos que cabalgan entre el universo oscuro de las pesadillas de Goya y una ínfima esperanza de encontrar la felicidad, para ella, relacionada con el amor y la libertad personal.

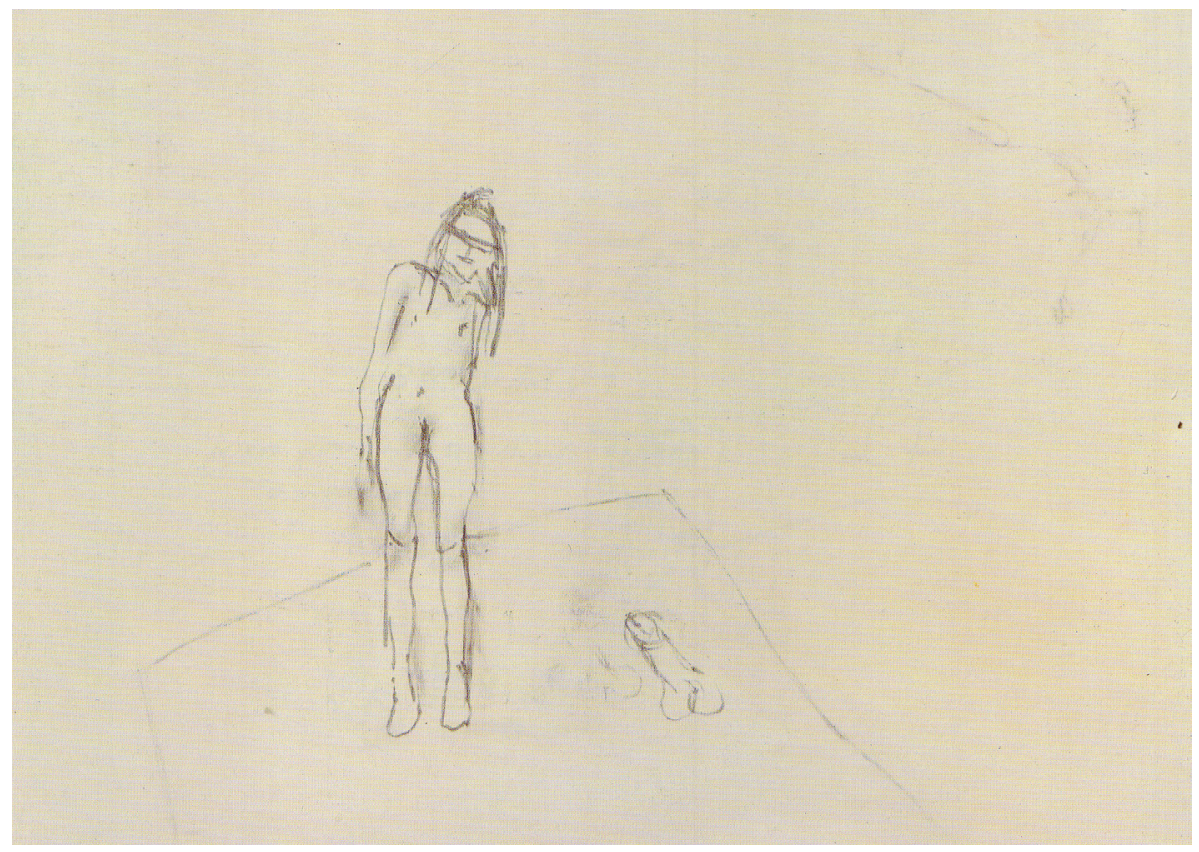

Figura 5. Tracey Emin, "Beautiful Child" ("Niño bonito"), 1999. (C) “One Thousand Drawing". 
"El dibujo es un lenguaje alquímico. Algunos de los dibujos favoritos que he realizado, los he hecho con los ojos cerrados" (Emin, Ghosts of my past / Los fantasmas de mi pasado, 2009). El automatismo en el proceso se apodera de ella, que suele trabajar desde el recuerdo, desde las imágenes que ha visionado en su mente en algún momento, y que de manera semiconsciente dispone sobre el papel. "Soy la que dirige las imágenes que viven en mi mente. Todas las imágenes primero han estado en mi cabeza y viajado a través de mi corazón, de mi sangre, llegando finalmente a mi mano" (Emin, Ghosts of my past, 2009). Un método instintivo vinculado al mundo surrealista en su procedimiento, aunque quede más ligado al expresionismo en su aspecto formal.

Los artistas que marcaron a Tracey Emin fueron indudablemente los expresionistas y su visión subjetiva de la realidad-naturaleza. Egon Schiele y Edvard Much serán los principales referentes para su trabajo gráfico, en el que destaca la línea, "una línea oscura y nerviosa que se ensombrece por las marcas y manchas causadas en parte por la presión de la pluma y en parte por los dedos o las manos de la artista al pasar por encima del papel. La línea se detiene y sangra, sugiriendo fragilidad y vulnerabilidad, como un corte o una cicatriz" (Elliott \& Schnabel, 2008, pág. 28). Un sentimiento de desarraigo y soledad lo inunda todo, donde, de manera sistemática quedan patentes sus preocupaciones con respecto al sexo. En Beautiful Child (Niño bonito), de 1999, vemos como se representa frente al hombre. La artista realiza un dibujo de una adolescente de pie, desnuda y de frente, sobre un espacio tridimensional que queda determinado por una especie de rectángulo en el suelo a modo de alfombra. La representación del hombre queda limitada a su órgano reproductor, lo ha simplificado y reducido a un elemento fálico. La comunicación entre ellos es nula, no sabemos si ha habido contacto o no, o si lo habrá en un futuro próximo, incomunicación que se traduce en incómoda tensión entre la pulsión de Eros y Tánatos.

La necesidad de verbalizar a través del dibujo sus dramas personales se convertirá en su particular terapia psicoanalítica. La visión dramática y voraz de representar la sexualidad y el erotismo hace que la línea que las separa de la pornografía sea sutil, "los criterios tradicionalmente empleados para establecer la distinción entre lo erótico y lo pornográfico no sólo carecen de base científica sino que, además, son fácilmente rebatibles en cuanto cambiamos de ámbito cultural o temporal. Dichos criterios son la dicotomía realidad/ficción, la falocracia y la elipsis o presencia visual". 


\section{La Transgresión, la Eliminación del Tabú y la Acción de la Memoria como Agente Reconstructivo}

En la tienda nos ofreció de manera tímida su vida privada, sus relaciones personales a través de la palabra, todas ellas, ocultas en el iglú. Después, en la performance que realiza en Estocolmo se oferta ella misma, invita a participar al espectador para que la observe. Y por último, en My bed muestra los residuos de varios días de excesos. Del modo tímido -que no introvertidoque se muestra al principio, sólo indicando las personas con las que había compartido su lecho, aclarando que no necesariamente habían sido encuentros sexuales, pasa a, sin ningún tipo de pudor, enseñar la propia cama, eliminando las palabras y mostrando el lugar del crimen.

Bajo estos tres eslóganes podríamos dirigirnos hacia los resultados finales de esta investigación. "La transgresión no es la negación de lo prohibido, sino que lo supera y lo completa" (Bataille G., 2007, pág. 67). Continuamente cruzando la frontera de lo establecido como decoroso en el subconsciente colectivo, hace que la transgresión sea una de las características más significativas y rápidamente visibles en su trabajo. Es capaz de decir lo que no se puede decir, lo que socialmente está prohibido, eliminando de este modo cualquier forma de tabú. Estos son sus lugares preferidos, los considerados sagrados, inviolables y sobre los que no se puede verbalizar por el resto de la gente. Ahí es donde Tracey Emin deposita toda su fuerza, se descarga de energía en estos espacios psicológicos sujetos a veto como si sólo de este modo pudiera obtener su redención.

Y así entra en juego la imaginación, una facultad parecida a un archivo de cualidades sensibles. A través de una experiencia somos capaces de reconstruir una totalidad. La fantasía nos permite la reconstrucción del concepto y no está sometida al tiempo. Con la imaginación podemos combinar los estímulos como pensemos oportuno y por eso es creadora, podemos coger un caballo y un hombre y fabricar un centauro, inventar mitos, quimeras, crear a Pegaso o titanes. Con los trabajos de Tracey Emin el público queda mudo, un silencio que usa como vehículo para llegar a otro lugar. Un lugar en el que la imaginación reconstruye el suceso, por lo que cada una de las obras será diferente para cada uno de los presentes, ya que sigue sujeta a la reconstrucción subjetiva por parte de éstos, utilizando la obra para verbalizar aspectos a los que nunca fue capaz de enfrentarse.

La decadencia, el declive, la pérdida de un camino vital, de su camino. Cada 
uno de sus trabajos acaba convirtiéndose en un grito de auxilio y cada uno de sus dibujos en uno de sus tantos episodios dolorosos. ¿Será esta confrontación con la realidad, a la que permanece sujeta el espectador, su pequeña venganza?

\section{Referencias}

Auster, P. (2009). La trilogía de Nueva York (22 ed.). Barcelona: Anagrama. Bataille, G. (1997). Las lágrimas de Eros. Madrid: Tusquets.

Bataille, G. (2007). El erotismo. Madrid: Tusquets.

Bernárdez, C. (2003). Joseph Beuys ( $3^{\mathrm{a}}$ ed.). San Sebastian: Nerea.

Blake, W. (1793). Las bodas del cielo y el infierno. Revista Culturamas.

Recuperado de http://www.culturamas.es/blog/2012/05/17/williamblake-el-matrimonio-del-cielo-y-el-infierno/

Choza, J. (2013). Filosofía de la cultura. Sevilla: Thémata.

Eliot, T. S. (2012). Cuatro cuartetos ( $8^{\mathrm{a}}$ ed.). (E. Pujals Gesalí, Trad.) Madrid: Cátedra.

Elliott, P., \& Schnabel, J. (2008). Tracey Emin 20 años. Málaga: CAC Málaga.

Emin, T. (25 de mayo de 2009). Ghosts of my past. The Guardian.

Recuperado el 14 de septiembre de 2013, de http://www.theguardian.

com/artanddesign/2009/may/25/tracey-emin-drawing-art

Freeman, C. (2006). Tracey Emin: Works 1963-2006. Nueva York: Rizzoli.

Gili, J. (2001). Muestras anuales. Plataformas y trampolines. Lápiz $(169 / 170), 122-127$.

Kierkegaard, S. (2007). El concepto de la angustia. (D. G. Rivero, Trad.) Madrid: Alianza Editorial.

Martín, F. J. (Diciembre de 2008). Tracey Emin. Un alma. Arte y parte (78), 25.

Nabokov, V. (2010). El ojo. (J. A. Masoliver Ródenas, Trad.) Barcelona: Anagrama.

Saltz, J. (1972). Seedbed. UbuWeb Film. Recuperado de http://www.ubu. $\mathrm{com} /$ film/acconci_seedbed.html 
Fernando Sáez Pradas: Personal Investigador en formación. Departamento de Dibujo. Universidad de Sevilla.

Contact Address: Facultad de Bellas Artes. C/Laraña n³, CP 41003 , Sevilla.

E-mail address: fsaez@us.es 